\title{
Performance Emulsifiable Vegetable Cutting Fluid Lubricant Vermicular Cast Iron Milling Process
}

\section{ISSN : 2688-836X}

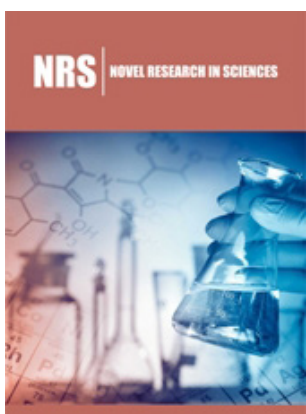

*Corresponding author: Sartori Moreno JR, Federal Technological University of Paraná, Mechanical Department, Cornelio Procópio, Brazil

Submission: September 04, 2019

Volume 2 - Issue 1

How to cite this article: Sartori Moreno JR and Lopes da Silva G. Performance Emulsifiable Vegetable Cutting Fluid Lubricant Vermicular Cast Iron Milling Process. Nov Res Sci.2(1). NRS.000526.2019. DOI: 10.31031/NRS.2019.2.000526

Copyright@ Sartori Moreno JR, This article is distributed under the terms of the Creative Commons Attribution 4.0 International License, which permits unrestricted use and redistribution provided that the original author and source are credited.

\author{
Sartori Moreno JR*1 and Lopes da Silva $\mathrm{G}^{2}$ \\ ${ }^{1} \mathrm{PhD}$ Federal Technological University of Paraná, Brazil \\ ${ }^{2}$ Professor MsC Federal Technological University of Paraná, Brazil
}

\begin{abstract}
The vegetable-based fluids have been increasingly used in industry because, in addition to pollute less cause less harm to the operator and provide a significant improvement in tool life. To perform this job temperature sensor adjustments were made on a simulation machine Reichert Wear Test type which has the function of providing simulations of friction and wear under controlled conditions, tests which were performed with vegetable oils lubrificants.
\end{abstract}

Keywords: Reichert test; Friction; Vegetable oils

\section{Methods}

Tribological tests are initial alternatives for analysis at the cutting fluid development stage, as they allow for greater flexibility in changing the fluid formulation where lubricity information is obtained. The performance of emulsifiable cutting fluid in the milling process of vermicular cast iron was evaluated. The results of the tribological tests through the Reichert test [1] were satisfactory, steadily and stable. The wear tests, the tung oil vegetable base showed lower yields in machining tests when compared to normal machining lubricants. This can be perfectly justified because the plant base of Tungue has no additives in its composition. These results point to the plant base of Tungue the possibility of new alternatives with renewable resources for application in the metalworking sector.

\section{Results}

The main results were related to the surface roughness of the workpiece in relation to the variables used in the tests. Therefore, as the output response, were obtained three roughness parameters $\left(R_{a^{\prime}} R_{q}\right.$ and $\left.R_{z}\right)$, which are factors that have influence on the texture and surface integrity of a workpiece. Figure $1(\mathrm{a} \& \mathrm{~b}$ ) show the average values of the roughness parameters $(\mu \mathrm{m}), \mathrm{R}_{\mathrm{a}^{\prime}} \mathrm{R}_{\mathrm{q}}$ and $\mathrm{R}_{\mathrm{z}}$ for all measurement ranges for wear edges 1 and 2 . By analyzing Figures 1 (a) has, at the end of the measurement interval, the average roughness Ra obtained for tung eluted with three measuring ranges with a surface roughness of $0.57 \mu \mathrm{m}$. However, it can be seen that the roughness values were found to incrementally, maintaining a proportion between the parameters evaluated, as in Figure 1b shows that for Tungue fluid, with three measuring ranges (ie, $2.16 \mathrm{~m}$ machined material) had a surface roughness $\left(\mathrm{R}_{\mathrm{a}}\right)$ of $0.60 \mu \mathrm{m}$. All these values always leading to improved surface finish compared to traditional machining fluids [2]. Analyzing Figure $1 \mathrm{a}(\mathrm{e}(\mathrm{b}))$ it can be observed that as the measurement intervals were being taken, the roughness values were increasing, maintaining a proportionality. Wear was progressively presented, which was reflected in the surface finish of the specimen, with loss of coating and/or a deterioration of the tool edge which in Figure 1b edge 2 showed a significant decrease in wear flank during the process [3]. 


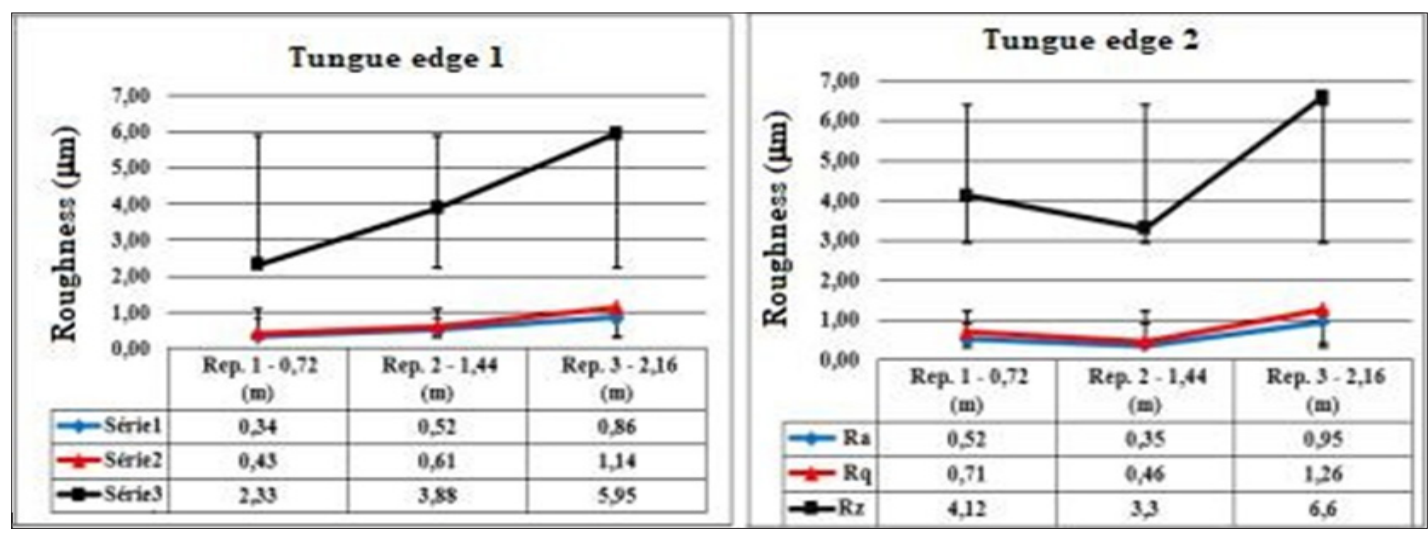

Figure 1: Roughness parameters $(\mu \mathrm{m}), \mathrm{R}_{\mathrm{a}}, \mathrm{R}_{\mathrm{q}}$ and $\mathrm{R}_{\mathrm{z}}$ for all measurement ranges for wear edges 1 and 2 .

\section{Discussion}

The main wear mechanism presented by the machining of this gray cast iron, using the vegetable base of Tungue as the cutting fluid, where abrasion wear, and the predominant type of wear was flank wear [4]. It was also noticeable the occurrence of adhesion on both the flank and the tool outlet surface. In some cases, less peeling/chipping and breakage of the cutting edges of the tools were noted when machining using Tungue vegetable-based fluid. Therefore, for edge 1 test conditions, the respective fluid showed an increase in final power consumption on average of $11.5 \%$ with a length of machined material. For edge 2, the vegetal base of the studied cutting fluid presented an $8.7 \%$ lower power consumption compared to the usual normal machining fluids [5].

\section{References}

1. Cakir MC, Cnsarioglu C, Demirayak I (2009) Mathematical modeling of 130 ribolog roughness for evaluating the effects of cutting parameters and coating material. Journal of Materials Processing Technology 209: 102-109.

2. Ampara A, Paul TM (2014) Critical factors in energy demand modelling for CNC milling and impact of tool path strategy. Journal of Cleaner Production 78: 63-74.

3. Wang J (2001) Development of a chip flow model for turning operations. International Journal of Machine Tools \& Manufacture 41(9): 12651274.

4. Tercheci M, Manory RR, Hensler JH (1995) The friction and wear automotive Grey cast iron under dry sliding conditions. Part 1 Relationships between wear loss and testing parameters. Wear 180(12): 73-78.

5. Ouza JF, Gomes JO, Souza J (2009) Vegetal-based cutting fluids evaluation in drilling compact Graphite Iron I. In: $16^{\text {th }}$ CIRP International Conference on Life Cycle Engineering (LCE 2009), Life Cycle Engineering in the Sustainability Age, Cairo. 